\section{Influence of testing environment on static fatigue behavior of a glass and a polycrystalline ceramic}

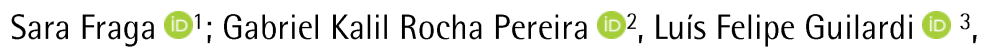

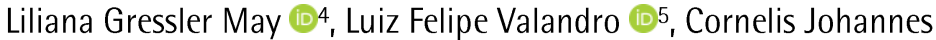
Kleverlaan ${ }^{106}$.

It aims on evaluate the effect of the test environment on static fatigue behavior of lithium disilicate-based (LD), and yttrium oxide-stabilized zirconia (YSZ) ceramics. Specimens of LD (IPS e.max CAD, Ivoclar Vivadent) and YSZ (IPS e.max ZirCAD M0, 3 mol\% Y203, Ivoclar Vivadent) were randomly allocated into three groups: tested in air, inert (paraffin oil, Sigma Aldrich) or distilled water. The static fatigue test $(n=15)$ was performed using a piston-on-three ball assembly, adapted from ISO 6872, as follows: starting load $100 \mathrm{~N}$ for LD and $300 \mathrm{~N}$ for YSZ; loading application time set to 1 hour for each loading step; step size of $50 \mathrm{~N}$ for LD and $100 \mathrm{~N}$ for YSZ, applied successively until fracture. Data from static fatigue strength (MPa) and time to fracture (hours) were recorded. Fractographic analysis was executed. Survival analysis corroborates absence of influence of environment on static fatigue outcomes (fatigue strength, time to fracture and survival rates) for YSZ. For LD, specimens tested in air presented statistically superior survival rate and static fatigue strength $(p=0.025)$. In regards of time to fracture, $L D$ tested in air were superior than when tested in distilled water $(p=0.019)$ or inert ( $p=0.017)$ environments. No statistical differences for Weibull modulus were observed. Failures started on the tensile stress surface. Thus, the test environment did not affect slow crack growth (SCG) mechanisms during static fatigue test of YSZ ceramics, but it plays a significant role for the static fatigue behavior of lithium disilicate-based glass ceramics, indicating a high susceptibility to SCG.
1 Federal University of Rio Grande do Sul Faculty of Dentistry, Department of Conservative Dentistry, Porto Alegre, RS, Brazil. sara.odonto@yahoo.com.br

2 Federal University of Santa Maria, Faculty of Dentistry, Department of Restorative Dentistry, Santa Maria, RS, Brazil.

gabrielkrpereira@hotmail.com

3 Federal University of Santa Maria, Faculty of Dentistry, Department of Restorative Dentistry, Santa Maria, RS, Brazil.

luisfguilardi@hotmail.com

4 Federal University of Santa Maria, Faculty of Dentistry, Department of Restorative Dentistry, Santa Maria, RS, Brazil. liligmay@gmail.com

$5^{*}$ Federal University of Santa Maria, Faculty of Dentistry, Department of Restorative Dentistry, Santa Maria, RS,Brazil.valandrolf@gmail.com

6 Academic Centre for Dentistry Amsterdam ACTA, Department of Dental Materials Science, Universiteit van Amsterdam and Vrije Universiteit, Amsterdam, The Netherlands. c.kleverlaan@acta.nl

Correspondence: Gabriel Kalil Rocha Pereira Federal University of Santa Maria, Faculty of Odontology, MDS-PhD Graduate Program in Oral Science, Prosthodontics Unit. Address: Avenue Roraima 1000, Building 26F, Room 2383, Zip-Code: 97105-900, Santa Maria, Rio Grande do Sul, Brazil. Fax: +55-553220-9210.

E-mail: gabrielkrpereira@hotmail.com

Key Words: dental ceramics, fatigue, slow-crack growth, subcritical crack growth, testing medium.

\title{
Introduction
}

The fracture of solids in response to load application is associated with little/no plastic deformation, or may be preceded by considerable plastic deformation, depending on the nature of the material (1). Ceramic materials are included in the first category being covered by the fields of Linear Elastic Fracture Mechanics (LEFM), and hence are considered as presenting a brittle nature $(1,2)$. Another consolidated presuppose in the literature is that the fracture strength of those brittle materials is known to be inversely proportional to the largest or critical flaw present in its volume, as described by Griffith's law (3).

Being so, any ceramic component when submitted to function will have to withstand mechanical stimuli without triggering rupture in order to increase the durability. However, under function, even in scenarios where they are loaded far below its critical load, continuously or under repetitive cycles, ceramic materials are known to surpass a phenomenon called "fatigue", which is often defined as the degradation (weakening) of a structural component under the influence of mechanical, chemical or biological stress - and in most cases - a combination of them (4).

As described by Cesar et al. (1), the definition of fatigue at ambient temperatures mostly involves two relevant mechanisms: stress corrosion and/or additional cyclic effects. Stress corrosion is related to sub-critical crack growth mechanisms (SCG), chemically assisted by water, and it deals with crack initiation and its slow growth under the influence of the environment. Cyclic effects arise from friction and hydrolytic pressure during crack closing. There is a common understanding that cyclic effects contribute to over-all degradation of brittle ceramics, although to lesser extent compared to SCG $(4,5,6)$. 
In response to variations on ceramic microstructure, different toughening mechanisms may be observed, hindering crack growth (e.g. crack bridging, crack deflection, or transformation toughening) $(1,4,7)$. The environment have an influence on the fatigue phenomena, specifically at SCG mechanisms, as a humid environment may trigger a corrosive process, where a diffusion-controlled attack of water molecules at the tip of a crack takes place, hydrolyzing siloxane bonds ( $\mathrm{Si}-\mathrm{O}-\mathrm{Si}$ ). Under mechanical loads the $\mathrm{Si}-\mathrm{O}-\mathrm{Si}$ bonds are strained, which further accelerates the hydrolytic reaction (8-12). This process occurs preferentially in silicate base glasses (13).

Since dental ceramics present different microstructure, the susceptibility to the SCG may vary greatly $(14,15)$. A study has shown that a lithium disilicate glass-ceramic (LD) was more susceptible to slow crack propagation than other vitreous ceramics, as porcelain and a heat press leucite-based glassceramic, presenting the lowest coefficient of SCG (15). As discussed by the authors, these results should be explained by the way that the lithium disilicate crystal were arranged during the heat-pressing procedure, resulting in a weak microstructure.

Literature in regards of the effect of the environment on SCG mechanism of yttrium oxide-stabilized zirconia (YSZ) ceramics, to the best of the authors knowledge, are scarce. YSZs are mainly polycrystalline ceramics that are absent of glassy composition (16). Thus, the degradation mechanism where humid environment would trigger hydrolyzation of siloxane bonds and facilitate SCG may be altered, or even absent. In fact, YSZ ceramics when submitted to stimuli may suffer a process named transformation toughening where crystals at tetragonal arrange convert into a monoclinic arrange expanding approximately $3-4 \%$ in volume, triggering residual stress concentration around surface defects and hindering the crack propagation (17-19). Thus, these presupposes justify an evaluation of how environment conditions (humid or not) may influence the fatigue performance of YSZ ceramics. Static fatigue test would potentiate to access such influence, isolating SCG mechanisms, as it eliminates the effect of cyclic mechanical loads triggering friction between walls and the deleterious consequences linked to such cyclic stimuli.

Based on that, the present study aimed to evaluate the effect of the test environment (distilled water, inert/oil, air) on the static fatigue behavior (strength and time to failure) of LD (a glass-ceramic) and YSZ (a polycrystalline ceramic). The assumed hypotheses were that 1) the test environment would affect the static fatigue behavior of LD ceramics, and 2) that the environment would not affect the static fatigue behavior of YSZ ceramics.

\section{Material and methods}

\section{Specimen preparation}

Pre-crystallized LD glass ceramic blocks (IPS e.max CAD LT, A2, C14 $(12 \times 14 \times 18 \mathrm{~mm})$, Ivoclar Vivadent, Schaan, Liechtenstein) and partially-sintered YSZ blocks (IPS e.max ZirCAD M0, C17 $(17 \times 19 \times 22 \mathrm{~mm}), 3 \mathrm{~mol} \% \mathrm{Y} 203$, Ivoclar Vivadent) were cut into rectangular specimens (lithium disilicate: $12 \times 14 \times 1.3 \mathrm{~mm}$; YSZ: $14 \times 17 \times 1.5 \mathrm{~mm}$, that is $20 \%$ larger to compensate the shrinkage after sintering) with a diamond disc in a saw machine (Isomet 1000; Buehler, USA), using a speed of 400rpm and no weight, under water cooling. Then the specimens were subsequentially manually polished with 400-, $600-$, and 1200- grit silicon carbide papers (20).

After polishing, the specimens were ultrasonically cleaned $(1440 \mathrm{D}, 50 / 60 \mathrm{~Hz}$, Odontobras, Ind. e Com.Equip. Med. Odonto. LTDA, Ribeirão Preto, São Paulo, Brazil) in isopropyl alcohol for $10 \mathrm{~min}$, and submitted to crystallization/sintering process, according to the manufacturer's instructions.

The crystallization of the lithium-disilicate specimens was performed according to the protocol indicated by the manufacturer (stand-by temperature $403^{\circ} \mathrm{C}$; closing time $6: 00 \mathrm{~min}$; heating rate t1 $90^{\circ} \mathrm{C} / \mathrm{min}$; firing temperature $\mathrm{T} 1820^{\circ} \mathrm{C}$; holding time $\mathrm{H} 1 \quad 0: 10 \mathrm{~min}$; heating rate t2 $30^{\circ} \mathrm{C} / \mathrm{min}$; firing temperature $\mathrm{T} 2840^{\circ} \mathrm{C}$; holding time $\mathrm{H} 27: 00 \mathrm{~min}$; vaccum $1550^{\circ} \mathrm{C}(11), 1022^{\circ} \mathrm{C}(12)$; vaccum $2820^{\circ} \mathrm{C}(21)$, $1508^{\circ} \mathrm{C}$ (22); long-term cooling $700^{\circ} \mathrm{C}$ ), using the furnace Programat P100 (Ivoclar Vivadent $A G$, Liechtenstein). Since the specimens were not glazed, no paste was used. The sintering of the YSZ specimens also followed the manufacturer's recommendations (maximum temperature $1500^{\circ} \mathrm{C} ; 2 \mathrm{~h}$ ), using a Cercon Heat furnace (DeguDent $\mathrm{GmbH}$, Hanau, Hesse, Germany).

The final dimensions of the specimens were $12 \times 14 \times 1.2 \pm 0.03 \mathrm{~mm}$. Finally, the specimens of each material were randomly allocated into three experimental groups, according to the environment condition considered during static fatigue test $(n=15)$ : air (ambient condition), inert medium (paraffin oil, Sigma Aldrich, St Louis, USA) and distilled water, as seen on Table 1. 


\begin{tabular}{|c|c|c|}
\hline Testing environment & $\begin{array}{l}\text { Ceramic material } \\
\text { Commercial Name * }\end{array}$ & Analysis \\
\hline \multirow{2}{*}{ Air } & $\begin{array}{l}\text { Lithium disilicate-base glass ceramic } \\
\text { IPS e.max CAD }\end{array}$ & \multirow{6}{*}{$\begin{array}{l}\text { Static fatigue test }(\mathrm{n}=15) \\
\text { Fractography (representative } \\
\text { samples for each group) }\end{array}$} \\
\hline & $\begin{array}{l}\text { Yttrium stabilized zirconia ceramic } \\
\text { IPS e.max ZirCAD MO }\end{array}$ & \\
\hline & $\begin{array}{l}\text { Lithium disilicate-base glass ceramic } \\
\text { IPS e.max CAD }\end{array}$ & \\
\hline Inert (Paratfin oil) " & $\begin{array}{l}\text { Yttrium stabilized zirconia ceramic } \\
\text { IPS e.max ZirCAD MO }\end{array}$ & \\
\hline \multirow{2}{*}{ Distilled Water } & $\begin{array}{c}\text { Lithium disilicate-base glass ceramic } \\
\text { IPS e.max CAD }\end{array}$ & \\
\hline & $\begin{array}{l}\text { Yttrium stabilized zirconia ceramic } \\
\text { IPS e.max ZirCAD MO }\end{array}$ & \\
\hline
\end{tabular}

\section{Static fatigue test}

The test was performed using a piston-on-three ball assembly, adapted from the ISO 6872 (21), in a universal testing machine (Instron 6022, Instron Corporation, USA), and considering the three different test environments described a priori at room temperature (approximately $20{ }^{\circ} \mathrm{C}$ ). The rectangular specimen was positioned on the top of the three steel spheres $\left(2.5 \mathrm{~mm}\right.$ diameter, $120^{\circ}$ apart, and forming a circle of $10 \mathrm{~mm}$ diameter), with a load applied perpendicular to the center of the top surface of the specimen, by a circular cylinder steel piston with a $1.4 \mathrm{~mm}$ diameter flat tip. To evenly distribute the contact pressures, a polyethylene film was placed between the supporting balls and the specimen; and between the specimen and the piston.

The static loading protocol started with $100 \mathrm{~N}$ for LD and $300 \mathrm{~N}$ for YSZ groups. The loading application time was set into 1 hour for each loading step. If the specimen survived, the stress was increased $50 \mathrm{~N}$ for LD and $100 \mathrm{~N}$ for YSZ, and then, successively until the fracture. The software was adjusted to register the load at fracture and the time to failure of each specimen. The static fatigue strength, in $\mathrm{MPa}$, of each specimen was calculated using Eqs. (1, 2 and 3) (21).

$$
\begin{array}{cc}
\sigma_{m}=-0.2387 P(X-Y) / b^{2} & \text { Eq. (1) } \\
X=(1+v) \ln (B / C)^{2}+[(1-v) / 2](B / C)^{2} & \text { Eq. (2) } \\
Y=(1+v)\left[1+\ln A / C^{2}\right]+(1-v)(A / C)^{2} & \text { Eq. (3) }
\end{array}
$$

where $P$ is the static load at fracture $(N), b$ is the thickness of the specimen $(\mathrm{mm}), A$ is the support ball radius $(5 \mathrm{~mm}), B$ is the radius of the tip of the piston $(0.7 \mathrm{~mm})$, and $C$ is the specimen radius $(6.5 \mathrm{~mm}$, corresponding to one-half of the edge length of the square plate specimens) (20). A specific Poisson ratio $(v)$ was used for each ceramic material (0.21 for LD; 0.26 for YSZ), based on the mean values obtained in the resonant ultrasound spectroscopy (RUS) methodology (22).

\section{Statistical analysis}

The static fatigue strength (in $\mathrm{MPa}$ ) and the time to fracture (in hours) were submitted to descriptive analysis. Weibull modulus (m) was calculated using maximum likelihood estimations at Super SMITH Weibull 4.0k-32 software program (Wes Fulton, Torrance, United States) to evaluate the influence of the test condition on the reliability of these variables (static fatigue strength and the time to fracture). Survival analysis (Kaplan Meier and Mantel-Cox post-hoc tests) were run at SPSS 21 statistical software (IBM, Chicago, USA), at a significance level of 5\%, was also used to investigate the effect of the test environment (air, inert, and distilled water) on static fatigue strength and the time to fracture of the YSZ and LD ceramics. The survival rates on each respective testing step were tabulated. 


\section{Fractography analysis}

After fatigue testing, the specimens were evaluated in an optical microscope (Stereo Discovery V20, Carl-Zeiss; Göttingen, Germany) at 100x of magnification to determine their crack characteristics and assure that the failure started at the side where tensile stress concentrates (21). Representative specimens of each group $(n=1)$ were ultrasonically cleaned $(1440 \mathrm{D}, 50 / 60 \mathrm{~Hz}$, Odontobras) in isopropyl alcohol for 10 minutes, entirely air-spray dried, sputtered with a gold-palladium alloy and subjected to scanning electron microscopy analysis (VEGA3 Tescan; Brno-Kohoutovice, Czech Republic) at high vacuum, 20kV, under 200x magnification.

\section{Results}

Kaplan Meier and Mantel cox post-hoc tests (Table 2, Figure 1) showed that the static fatigue strength $(p=0.345)$ and time to fracture $(p=0.698)$ of the YSZ ceramic were not influenced by the test environment. For LD glass ceramic, the group tested in air presented a significantly higher static fatigue strength than the group tested in distilled water $(p=0.025)$. In regards of time to fracture, $L D$ discs tested in air were significantly superior to the ones tested under distilled water $(p=0.019)$ or inert $(p=0.017)$ environments (Table 2, Figure 1). Weibull modulus of LD and YSZ ceramics were not influenced by the test environment (Table 2).

Table 2. Fatigue test results considering static fatigue strength and time to fracture variables - Mean and Standard deviation; Weibull modulus with its respective 95\% confidence interval.

\begin{tabular}{|c|c|c|c|c|c|}
\hline \multirow{2}{*}{ Ceramic } & \multirow{2}{*}{ Testing environment } & \multicolumn{2}{|c|}{ Static fatigue strength } & \multicolumn{2}{|c|}{ Time to fracture } \\
\hline & & Mean (SD) in $\mathrm{MPa}^{*}$ & Weibull Modulus*** & Mean (SD) in $\mathrm{h}^{*}$ & Weibull Modulus*** \\
\hline \multirow{3}{*}{ YSZ } & Air & $961(163)^{\mathrm{A}}$ & $6.22(3.59-8.69)^{\mathrm{A}}$ & $3.34(1.13)^{\mathrm{A}}$ & $2.89(1.67-4.04)^{\mathrm{A}}$ \\
\hline & Inert & $1,011(113)^{\mathrm{A}}$ & $10.45(6.03-14.59)^{\mathrm{A}}$ & $3.58(0.7)^{\mathrm{A}}$ & $5.81(3.36-8.12)^{\mathrm{A}}$ \\
\hline & Distilled Water & $951(134)^{\mathrm{A}}$ & $8.52(4.92-11.90)^{\mathrm{A}}$ & $3.28(0.87)^{\mathrm{A}}$ & $4.26(2.46-5.95)^{\mathrm{A}}$ \\
\hline \multirow{3}{*}{ LD } & Air & $388(72)^{\mathrm{A}}$ & $5.85(3.38-8.17)^{\mathrm{A}}$ & $3.51(1.0)^{\mathrm{A}}$ & $4.32(2.49-6.03)^{\mathrm{A}}$ \\
\hline & Inert & $350(62)^{A B}$ & $6.03(3.48-8.42)^{\mathrm{A}}$ & $2.88(0.94)^{\mathrm{B}}$ & $2.79(1.61-3.90)^{\mathrm{A}}$ \\
\hline & Distilled Water & $340(69)^{\mathrm{B}}$ & $5.57(3.22-7.78)^{\mathrm{A}}$ & $2.87(0.76)^{\mathrm{B}}$ & $4.32(2.49-6.03)^{\mathrm{A}}$ \\
\hline
\end{tabular}

*different letters indicate statistical differences depicted by Kaplan Meier and Mantel-Cox post-hoc tests (significance level = 5\%). ** similar letters indicate absence of statistical differences depicted by the overlapping of confidence intervals for Weibull parameters (maximum-likelihood estimation). 

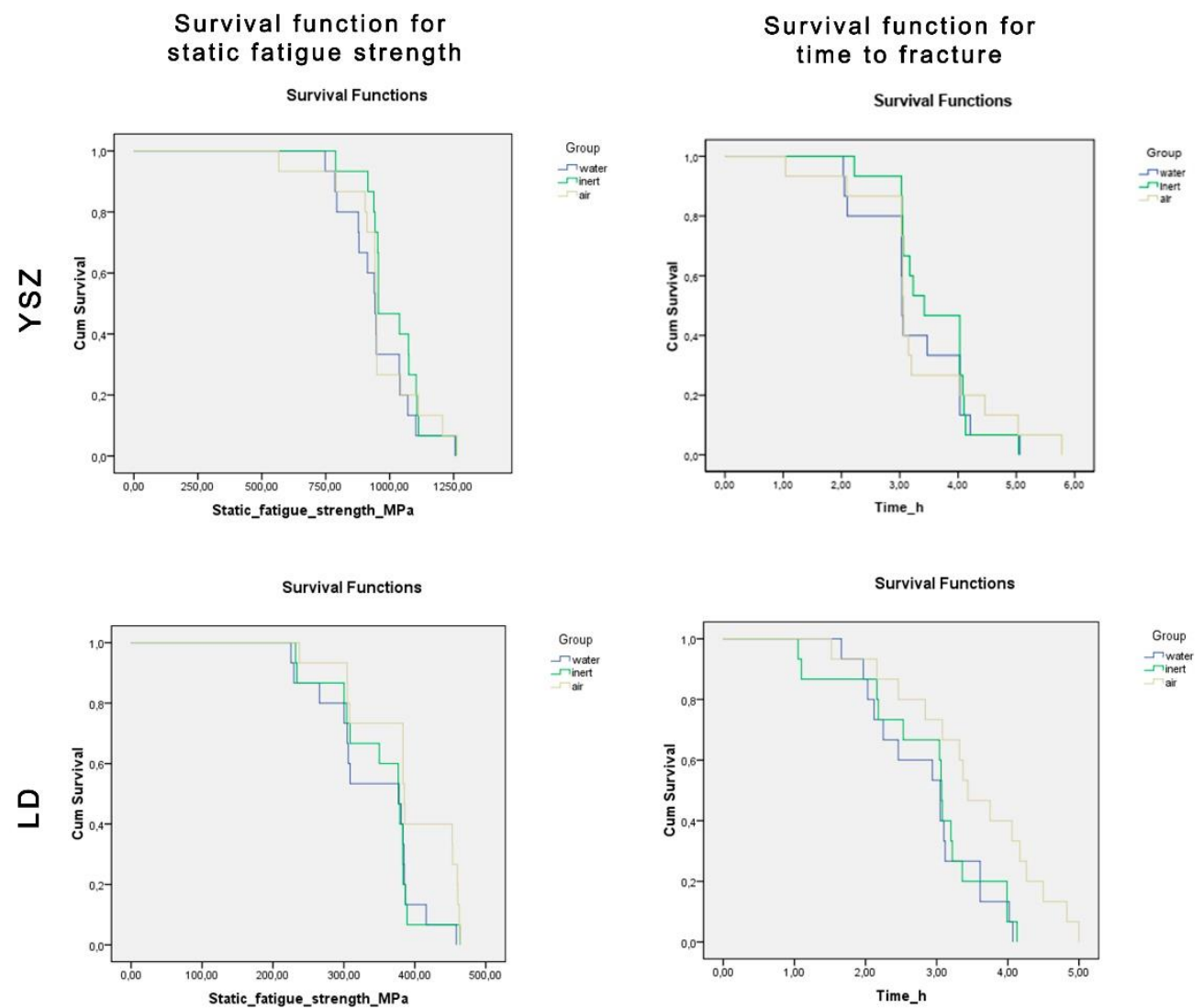

Figure 1. Survival graphs obtained through Kaplan Meier analysis of the fatigue data for YSZ and LD ceramics on the three test environments.

Fractographic images shows that all failures started on the side where tensile stress concentrates (downside) during testing (Figure 2).
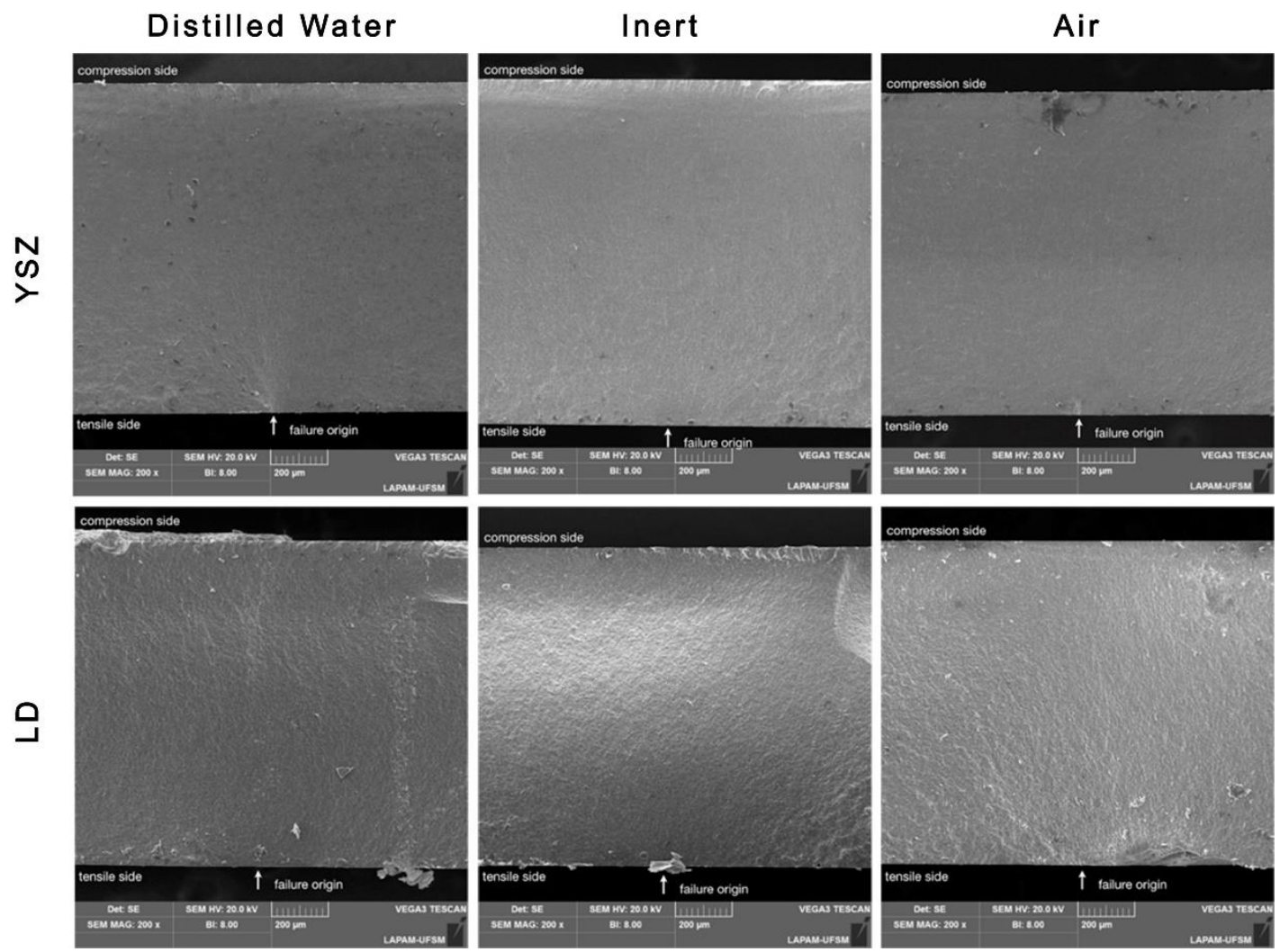

Figure 2. Fractographic images (200x of magnification) for YSZ and LD ceramics under the three test environments. Hackle lines radiating from the fracture origin can be seen in all images. The white arrow points to the failure origin on the side where it concentrates tensile stresses during testing, which than propagated to the opposite side. 


\section{Discussion}

Lithium disilicate glass-ceramic and YSZ are the most widely used materials for indirect all ceramic restorations (23), which emphasizes the importance of knowing better their mechanical behavior. The results of the present study showed that the test environment did not affect the static fatigue behavior of the YSZ ceramic. Meanwhile, in regards of the LD glass-ceramic performance, the static fatigue strength and the time to fracture were significantly reduced by the presence of distilled water. Therefore, the hypotheses of the present study were validated.

Material's microstructure plays an important role in the mechanical behavior of dental ceramics $(14,15)$. It is known that polycrystalline ceramics are less susceptible to slow crack growth phenomenon $(1,24)$ than glassy materials, since they present almost absent of glassy composition, that optimizes toughening mechanisms and difficult crack growth (e.g. crack bridging, crack deflection, and transformation toughening, where the latter being specific to YSZ) $(4,7,19)$.

Water, either in liquid or as a vapor, is the most common medium that stimulates slow crack growth on materials that present hydrolyzing siloxane bonds (Si-0-Si) $(8-12,25)$. The molecules of water chemically react with the strained atomic bonds at the crack tip, inducing a stress corrosion, and weakening the material. To control the effect of the water in this process, an inert medium may be used, being possible to evaluate the influence of the test environment in the fatigue behavior of dental glassbased ceramics. This inert environment may be provided by using some substances, as oils. In the present study, the use of a paraffin oil might not completely eliminate the influence of the SCG for lithium disilicate specimens, in concordance with Anusavice and Lee (26), suggesting a high susceptibility of crack propagation for glassy dental ceramics.

Despite that, based on the present data, when considering polycrystalline ceramics, as YSZ, the environment did not play a significant role on SCG mechanisms. In fact, it should be considered that the presence of moisture during testing may trigger phase transformation mechanisms in YSZ materials that may lead to even optimized performance, as shown in many existing papers $(18,27-29)$. The presence of increased $m$-phase content may be deleterious only when the amount of $m$-phase becomes extremely high, where some corroborates such outcome only when the quantity surpasses at least $50 \%$ of mcontent $(30,31)$.

A recent study has shown that YSZ performs better than LD in terms of resistance to stress corrosion (14), which agrees with the present results. The high content of glass (SiO2) in lithium disilicate ceramics, makes this material highly sensitive to SCG process.

The static fatigue method is characterized by a constant stress over the time (13). By this test, it is possible to eliminate the effect of cyclic mechanical loads, isolating the effect of the environment on stress corrosion. Considering the huge difference in the biaxial flexural strength of lithium disilicate (647.98 MPa) and YSZ (1240.89 MPa) (32), a different loading protocol was established for each material, making data collection feasible. The loading values, in Newtons, were based on a previous study, in which the first loading step (100 N for LD, and $300 \mathrm{~N}$ for YSZ), resulted in a survival rate of $100 \%$, in a cyclic fatigue test ( 500.000 cycles; $1.4 \mathrm{~Hz})(33)$. The time of one hour in each loading step is equivalent to the time necessary to complete 10,000 loading cycles at $2 \mathrm{~Hz}$, in a cyclic fatigue test, a protocol used in other fatigue studies (34).

In the present study, specimens with a rectangular geometry were used to optimize specimen preparation and to reduce costs (35). Finite element analysis has shown that the pattern of stress distribution is very similar between discs and square shaped ceramic samples tested in a piston-on-three ball configuration (20). The highest tensile stress concentration, where the fracture usually starts, appears in the lower surface of the specimen, in the central region among the supporting balls (20). A good agreement between the biaxial flexural strength values for different geometries of ceramic specimens tested in a ball-on-three-ball setup was also reported (32).

Optical tools such as stereo microscope and SEM can be used to perform qualitative fractography, by means of the recognition of surface crack features that indicate the direction of crack propagation and fracture origin, as compression curl and mirror zone (36). In the present study, the fractography analysis was performed to assure that the fracture started at the side where tensile stress concentrates, and not from the compressive site. The determination of the type of defect that originate the fracture (e.g. pore, scratches, crack) was not the aim of the present study.

Therefore, the present data corroborate that fatigue tests of YSZ ceramics may be adequately run under any environment to stimulate fatigue without bias, meanwhile, for LD, and potentially for other glassy materials, the influence of the environment should be considered to set the adequate testing method. 
Considering the limitations of this in vitro study, it can be concluded that the test environment did not affect the static fatigue behavior (strength and time to failure) of YSZ ceramics. Meanwhile, the test environment plays a significant role for the static fatigue behavior of lithium disilicate-based glass ceramics, indicating a high susceptibility to SCG.

\section{Acknowledgements}

The authors declare that this study was financed in part by the Brazilian Federal Agency for Coordination of Improvement of Higher Education Personnel (CAPES) by means of CAPES-PrInt program (Program for institutional internationalization - Call 41/2017). We especially thank Ivoclar Vivadent for donating the research materials. Finally, we emphasize that those institutions had no role in the study design, data collection or analysis, decision to publish or in preparing the manuscript.

\section{Resumo}

0 presente estudo objetivou investigar a influência do ambiente de teste no comportamento a fadiga estática (resistência à fratura e tempo para falha) de cerâmicas à base de dissilicato de lítio (LD) e zircônia estabilizada com ítria (YSZ). Espécimes de LD (IPS e.max CAD, Ivoclar Vivadent) e YSZ (IPS e.max ZirCAD M0, 3mol\% Y203, Ivoclar Vivadent) foram obtidos e alocados aleatoriamente em três grupos: testado em ar, em líquido inerte (óleo de parafina) ou em água destilada. 0 teste de fadiga estática ( $n=$ 15) foi realizado usando o teste pistão sobre três esferas, ISO 6872, da seguinte forma: carga inicial 100 $\mathrm{N}$ para LD e $300 \mathrm{~N}$ para YSZ; tempo de aplicação de carregamento definido para 1 hora para cada etapa de carregamento; tamanho do passo de $50 \mathrm{~N}$ para LD e $100 \mathrm{~N}$ para YSZ, aplicados sucessivamente até a fratura. Dados de resistência à fadiga estática ( $\mathrm{MPa}$ ) e tempo até a fratura (horas) foram registrados. A análise fractográfica foi executada. A análise de sobrevivência corrobora a ausência de influência do ambiente de teste nos resultados de fadiga estática (resistência à fadiga, tempo de fratura e taxas de sobrevivência) para a YSZ. Para LD, os corpos de prova testados em ar apresentaram taxa de sobrevivência e resistência à fadiga estática estatisticamente superiores $(p=0,025)$. Em relação ao tempo de fratura, os espécimes $L D$ testados em ar foram superiores aos testados em água destilada $(p=0,019)$ ou em ambiente inerte $(p=0,017)$. Não foram observadas diferenças estatísticas para o módulo de Weibull. Todas as falhas começaram no lado onde se concentra a tensão de tração (lado de baixo) durante o teste. Com base nisso, observa-se que o ambiente de teste não afetou os mecanismos de crescimento lento de trinca durante o teste de fadiga estática da cerâmica YSZ, mas desempenha um papel significativo na resistência à fadiga estática da cerâmica de vidro à base de dissilicato de lítio, indicando alta susceptibilidade ao crescimento lento e subcrítico de trincas. 


\section{References}

1. Cesar PF, Della Bona, A. Scherrer, SS. Tholey, M. van Noort, R. Vichi, A. Kelly, R. Lohbauer, U. ADM guidance-ceramics: fracture toughness testing and method selection. Dent Mater 2017 33:575-584.

2. Barsoum MW. Introduction. In: Barsoum, MW., (1st ed.), Series in Material Sciences and Engineering - Fundamentals of ceramics. CRC Press, Boca Raton, Florida, 2002;pp.1-12.

3. Griffith AA. The phenomena of rupture and flow in solids. Philos Trans A Math Phys Eng Sci 1921;221:582-593.

4. Kelly JR, Cesar PF, Scherrer SS, Della Bona A, van Noort R, Tholey M, Vichi A, Lohbauer U. ADM guidance-ceramics: Fatigue principles and testing. Dent Mater 2017 33:1192-1204.

5. Danzer, R. Lube, T. Supancic, P. Damani, R. Fracture of ceramics. Adv Eng Mater 2008;10:275-298.

6. Evans AG. Slow crack growth in brittle materials under dynamic loading conditions. Int J Fract 1974;10:251-259.

7. Kruzic JJ, Arsecularatne JA, Tanaka CB, Hoffman MJ, Cesar PF. Recent advances in understanding the fatigue and wear behavior of dental composites and ceramics. J Mech Behav Biomed Mater 2018;88:504-533.

8. Joshi GV, Duan Y, Della Bona A, Hill TJ, St. John K, Griggs JA. Fatigue loading and R-curve behavior of a dental glass-ceramic with multiple flaw distributions. Dent Mater 2013;29:1123-1131.

9. Freiman SW, Wiederhorn SM, Mecholsky JJJ. Environmentally enhanced fracture of glass: a historical perspective. J Am Ceram Soc 2009;92:1371-1382.

10. Wiederhorn SM, Bolz LH. Stress corrosion and static fatigue of glass. J Am Ceram Soc 1970;53:543548.

11. Wiederhorn SM. Influence of water vapor on crack propagation in soda-lime-glass. J Am Ceram Soc 1967;50:407-414.

12. Charles RJ. Static fatigue of glass. J Appl Phys 1958;29:1549-1560.

13. Kelly JR, Cesar PF, Scherrer SS, Della Bona A, van Noort R, Tholey M, Vichi A, Lohbauer U. ADM guidance-ceramics: Fatigue principles and testing. Dent Mater 2017;33:1192-1204.

14. Liu C, Eser A, Albrecht T, Stournari V, Felder M, Heintze S, Broeckmann C. Strength characterization and lifetime prediction of dental ceramic materials. Dent Mater 2020; Nov 15.

15. Gonzaga CC, Cesar PF, Miranda Jr WG, Yoshimura HN. Slow crack growth and reliability of dental ceramics. Dent Mater 2011;27:394-406.

16. Kelly JR. Dental ceramics: what is this stuff anyway? J Am Dent Assoc 2008;139, Suppl:4S-7S.

17. Hannink R, Kelly $P$, Muddle B. Transformation toughening in zirconia containing ceramics. J Am Ceram Soc 2000;83:461-487.

18. Piconi C, Maccauro G. Zirconia as a ceramic biomaterial. Biomaterials 1999;20:1-25.

19. Chevalier J, Olagnon C, Fantozzi G. Subcritical crack propagation in 3YSZ ceramics: static and cyclic fatigue. J Am Ceram Soc 1999;82:3129-3138.

20. Ramos JS, Fraga S, Vogel GF, May LG. Influence of the geometry of ceramic specimens on biaxial flexural strength: experimental testing and finite element analysis. Ceramica 2018;64:120-125.

21. ISO 6872. Dentistry-Ceramic Materials (4rd ed.) International Organization for Standardization, Geneva, 2015;pp.1-28.

22. Belli $R$, Wendler M, de Ligny D, Cicconi MR, Petschelt A, Peterlik $H$, Lohbauer U. Chairside CAD/CAM materials. Part 1: measurement of elastic constants and microstructural characterization. Dent Mater 2017;33:84-98.

23. Belli R, Petschelt A, Hofner $B$, Hajtó J, Scherrer SS, Lohbauer U. Fracture rates and lifetime estimations of CAD/CAM all-ceramic restorations. J Dent Res 2016;95:67-73.

24. Amaral M, Weitzel ISSL, Silvestri T, Guilardi LF, Pereira GKR, Valandro LF. Effect of grinding and aging on subcritical crack growth of a Y-TZP ceramic. Braz Oral Res 2018;32:e32.

25. Quinn GD. NIST recommended practice guide. Fractography of ceramics and glasses. (Special Publication 960-16e2). National Institute of Standards and Technology, Washington, 2016;pp.640.

26. Anusavice KJ, Lee RB. Effect of firing temperature and water exposure on crack propagation in unglazed porcelain. J Dent Res 1989;68:1075-1081.

27. Pereira GKR, Muller C, Wandscher VF, Rippe MP, Kleverlaan CJ, Valandro LF. Comparison of different low-temperature aging protocols: its effects on the mechanical behavior of Y-TZP ceramics. J Mech Behav Biomed Mater 2016;60:324-330.

28. Guilardi LF, Pereira GKR, Wandscher VF, Rippe MP, Valandro LF. Mechanical behavior of yttriastabilized tetragonal zirconia polycrystal: Effects of different aging regimens. Braz Oral Res 2017;31:e94. 
29. Silvestri T, Pereira GKR, Guilardi LF, Rippe MP, Valandro LF. Effect of Grinding and Multi-Stimuli Aging on the Fatigue Strength of a Y-TZP Ceramic. Braz Dent J 2018;29:60-67.

30. Pereira GKR, Venturini AB, Silvestri T, Dapieve KS, Montagner AF, Soares FZM, Valandro LF. Lowtemperature degradation of Y-TZP ceramics: A systematic review and meta-analysis. J Mech Behav Biomed Mater 2015;55:151-163.

31. Chevalier, J. Gremillard, L. Deville, S., 2007. Low-Temperature Degradation of Zirconia and Implications for Biomedical Implants. Annual Review of Materials Research 37:1-32.

32. Wendler M, Belli R, Petschelt A, Mevec D, Harrer W, Lube T, Daner R, Lohbauer U. Chairside CAD/CAM materials. Part 2: Flexural strength testing. Dent Mater 2017 33:99-109.

33. Fraga $S$, Amaral M, Bottino MA, Valandro LF, Kleverlaan CJ, May LG. Impact of machining on the flexural fatigue strength of glass and polycrystalline CAD/CAM ceramics. Dent Mater 2017; 33:12861297.

34. Velho HC, Dapieve KS, Pereira GKR, Fraga S, Valandro LF, Venturini AB. Accelerated loading frequency does not influence the fatigue behavior of polymer infiltrated ceramic network or lithium disilicate glass-ceramic restoration. J Mech Behav Biomed Mater 2020 110:103905.

35. Guilardi LF, Soares P, Werner A, de Jager N, Pereira GKR, Kleverlaan CJ, Rippe MP, Valandro LF. Fatigue performance of distinct CAD/CAM dental ceramics. J Mech Behav Biomed Mater 2020;103:103540.

36. Scherrer SS, Lohbauer U, Della Bona A, Vichi A, Tholey MJ, Kelly JR, Van Noort R, Cesar PF. ADM guidance - Ceramics: guidance to the use of fractography in failure analysis of brittle materials. Dent Mater 2017, 33:599-620. 